\title{
PENGARUH PARTISIPASI ANGGARAN TERHADAP SLACK ANGGARAN DENGAN PENEKANAN ANGGARAN DAN KETIDAKPASTIAN LINGKUNGAN SEBAGAI VARIABEL MODERATING (SURVEI PADA HOTEL BERBINTANG DI KOTA BOGOR)
}

\section{THE EFFECT OF BUDGET PARTICIPATION ON SLACK BUDGETARY WITH BUDGET EMPHASIS AND THE UNCERTAINTY OF THE ENVIRONMENT AS MODERATING VARIABLE ON THE LUXURY HOTELS IN THE CITY OFBOGOR}

\author{
I.C. Kusuma, H. Hidayat \\ Program Studi Akuntansi Fakultas Ekonomi Universitas Djuanda Bogor \\ J1. Tol Ciawi No.1, Kotak Pos 35, Kode Pos 16720, Telp/Fax:0251.8245155 \\ E-mail: indra.cahya.kusuma@unida.ac.id, hendri.hidayat@unida.ac.id
}

\begin{abstract}
ABSTACT
This study aimed to examine the effect of budget participation on slack budgetary with budget emphasis and the uncertainty of the environment as moderating variable on the luxury hotels in the city of Bogor. Designs in this research is quantitative method with the approach of causality or causal. This research is using purposive sampling method, the number of samples in this study were 48 respondents. Methods of data analysis using multiple regression analysis by SPSS 20.0 software program.The results shows that budget participation give negative effect and significant on the budget slack and environmental uncertainty moderating (strengthening) the relationship of participation to the slack budget. while budget emphasis on the research is not a moderating variable. Simultaneously budget participation, budget emphasis and environmental uncertainty had a significant effects on the slack budget.
\end{abstract}

Keywords: Budget Participation, budget emphasis, environmental uncertainty and slack budget.

\begin{abstract}
ABSTRACK
Penelitian ini bermaksud menguji pengaruh partisipasi anggaran pada slack anggaran melalui pengkhususan anggaran serta ketidakpastian lingkungan sebagai variabel moderating. Desain penelitian yaitu metode kuntitatif dengan pendekatan hubungan kausalitas atau sebab akibat. Sampling pada penelitian ini menggunakan purposive sampling, jumlah sampel dalam penelitian ini berjumlah 48 responden. Metode analisis data dengan menggunakan analisis regresi berganda dengan bantuan program software SPSS 20.0. Hasil penelitian menjelaskan partisipasi anggaran berpengaruh negatif dan signifikan terhadap slack anggaran dan ketidakpastian lingkungan memperkuat hubungan partisipasi padaslack anggaran. Sedangkan penekanan anggaran bukan variabel moderasi. Secara simultan partisipasi anggaran, pengkhususan anggaran serta ketidakpastian lingkungan berpengaruh dan signifikan terhadap slack anggaran.
\end{abstract}

Kata kunci: Partisipasi anggaran, penekanan anggaran, ketidakpastian lingkungan serta slack anggaran. 


\section{PENDAHULUAN}

Semakin pesat tingkat kunjungan wisatawan di Bogor, membuat pertumbuhan yang cukup pesat pada bisnis perhotelan, khususnya Kota Bogor yang merupakan kota kecil namun terkenal dengan suasana yang masih sejuk, pariwisata, dan kuliner yang beragam yang sangat disukai wisatawan-wiatawan, baik lokal maupun mancanegara. Kondisi seperti ini membuat perkembangan kunjungan pada hotel di Kota Bogor yang mengalami tingkat pertumbuhan yang positif. Oleh karena itu, bisnis perhotelan di Kota Bogor mengalami kompetisi yang relatif ketat dan kompetitif. Pertumbuhan tingkat wisatawan yang berkunjung di hotelhotel Kota Bogor tercermin dalam data pertumbuhan pada tahun 2008-2014 dalam Tabel 1.1 berikut :

Tabel 1.1 Data Perkembangan Kunjungan Wisatawan dan Menginap di Hotel Kota Bogor

Tahun 2008-2015

\begin{tabular}{ccccccc}
\hline \multirow{2}{*}{ Tahun } & \multicolumn{3}{c}{ Kunjungan ke obyek wisata } & \multicolumn{3}{c}{ Menginap di Hotel } \\
\cline { 2 - 3 } & \multicolumn{2}{c}{ Wisatawan/Tourist } & \multirow{2}{*}{ Total } & Domestic & Mancanegara & \multirow{2}{*}{ Total } \\
\hline 2008 & 1370119 & 18174 & 1388293 & 716807 & 31443 & 748250 \\
2009 & 1163110 & 42377 & 1205487 & 1086374 & 102737 & 1189111 \\
2010 & 1524044 & 42812 & 1566856 & 1205628 & 104076 & 1309704 \\
2011 & 1630687 & 43837 & 1674524 & 1190793 & 102055 & 1292848 \\
2012 & 1802539 & 45618 & 1848157 & 1309875 & 106137 & 1416012 \\
2013 & 996880 & 58491 & 1055371 & 2428331 & 108515 & 2536846 \\
2014 & 1137575 & 71032 & 1208607 & 2632212 & 112775 & 2744987 \\
2015 & 2429470 & 36496 & 2465966 & 1168263 & 165612 & 1333875 \\
\hline
\end{tabular}

Sumber : Dinas Kebudayaan dan Pariwisata Kota Bogor (2016)

Semakin berkembang dan kompetitifnya dalam bisnis perhotelan, pada dasarnya dicapai karena keterampilan manajemen saat mengawasi, mengendalikan, dan meramalkan beberapa kemungkinan serta kesempatan yang baik untuk jangka panjang. Salah satu faktor yang menentukan kesuksesan ataupunkemunduran suatu perusahaan dalam kegiatan usahanya adalah bagaimana manajemen perusahaan khususnya dibidang keuangan yang mengendalikan dana yang tersedia ataupun yang diperkirakan akan diterima sebagaimana catatan arus kas ataupun pada bank efektif dan efisien. Peranan manajemen dalam operasionalisasi perusahaan mampu melakukan fungsi manajemen atas keputusannya yaitu perencanaan, pengorganisasian, pengarahan, koordinasi serta pengendalian, dan aktivitas manajemen yang paling penting yaitu upaya untuk menciptakan suatu sistem pengendalian dan terperinci yaitu dengan fungsi perencanaan dan pengendalian (Munandar, 2010:16). Oleh sebab itu, anggaran digunakan oleh manajemen untuk acuan menggapai kesuksesan yang sudah digariskan sebelumnya.

Nafarin (2004:12) mendefinisikan bahwa anggaran ialah sebuah maksud keuangan pada periode disusun pada rencana yang disahkan. Anggaran ialah maksud yang ditulis berdasarkan kegiatan organisasi dinyatakan secara kuantitatif dan umum dijelaskanpada satuan uang pada periode tertentu. Anggaran ialah elemen penting pada perencanaan serta pengendalian. Sebagai perlengkapan perencanaan, anggaran dipakai untuk mengatur kegiatan pusat berkewajiban dalam suatu pelaksanaan kegiatan sesuai dengan yang direncanakan manajemen. Tidak hanya itu, fungsinya untuk 
alat perencanaan, anggaran terbagi menjadi beberapa sasaran yang dicapai manajer pada suatu perusahaan dalam melakukan kegiatan di masa datang. Penyusunan anggaran memerlukan partisipasi dari anggota organisasi atau manajemen yaang terpengaruh disebut partisipasi anggaran (participative budgeting).Horngren, $\mathrm{dkk}$ (2014:282) mengemukakan partisipasi anggaran yaitu anggaran yang dibuat dengan partisipasi aktif semua karyawan yang terpengaruh. Partisipasi anggaran mengikut sertakan manajemen menjabarkan perencanaan anggaran.

Aspek keprilakuan penganggaran mengerahkan pada timbulnya perilaku individu/organisasi. Perilaku-perilaku tampak pada partisipasi anggaran bisa bersifat positif dan negatif. Peningkatan kinerja karena motivasinya pada anggaran dipakai selaku dasar penilaian kinerja diartikan sebagai Perilaku yang positif. Perilaku negatif yang memungkinkan muncul yaitu kecenderungan untuk menginformasikan informasi bias dalam partisipasi dan membuat kelonggaran pada anggaran yang cenderung menerapkan slack dalam anggaran. Perilaku ini biasanya relatif dilakukan manajer yang cenderung membuat slack pada anggaran. Jika organisasi menggunakan anggaran sebagai target evaluasi kinerja, manajer memiliki insentif tambahan untuk berbohong. Manajer memiliki insentif menciptakan slackanggaranyaitu dengan melebih sajikan biaya yang dianggarkan atau mengurang sajikan pendapatan yang dianggarkan demi menciptakan target anggaran yang lebih mudah dicapai (Horngren, dkk, 2014:283).

Slack yaitu selisih antara sumber daya sebenarnya diperlukan efisien menyelesaikan tugas serta jumlah sumber daya yang lebih besar yang diperuntukan bagi tugas tersebut, dengan kata lain slack ialah penggelembungan anggaran (Ishak dan Ikhsan, 2005:176). Jika organisasi menggunakan anggaran sebagai target evaluasi kinerja, manajer memiliki insentif tambahan untuk berbohong. Manajer memiliki insentif membuat slack anggaran yaitu melebih sajikan biaya yang dianggarkan atau mengurang sajikan pendapatan yang dianggarkan demi menciptakan target anggaran yang lebih mudah dicapai (Horngren et al, 2014:283). Slack anggaran juga membantu menyangga manajer dari pemotongan anggaran manajemen tingkat tinggi dan menyediakan perlindungan terhadap peningkatan biaya atau penurunan pendapatan sebagai dampak yang tidak terduga.

\section{METODE PENELITIAN}

Desain penelitian yaitu metode kuantitatif dengan pendekatan hubungan kausalitas. Kausalitas atau kausal yaitu hubungan yang bersifat sebab akibat. Dimana ada variabel independen (variabel yang mempengaruhi) dan variabel dependen (dipengaruhi), Sugiyono (2016:37). Pengunaan data ialah data primer yang didapatkan langsung dengan metode survey dan menyebarkan kuesioner kepada responden serta diolah dan diuji melalui SPSS 20.0 for windows.

\section{Variabel Penelitian}

\section{Variabel Independen (Variabel X)}

Variabel independen yaitu variabel yang menjadi sebab perubahan variabel terikat (Juliansyah, 2011:48-49). Variabel terikat / Independen adalah Partisipasi anggaran $\left(\mathrm{X}_{1}\right)$ pengukuran dilakukan dengan 6 item indikator yang di kembangakan oleh Milani, 1975 dalam Triana, et al, 2012. Dengan skala likert 1-5.

\section{Varibel Moderating :}

Penekanan Anggaran $\left(\mathrm{X}_{2}\right)$. Pengukuran dilakukan dengan 8 item indikator pertanyaan yang di kembangkan oleh Hopwood, 1972 
dalam Triana, et al, 2012. Dengan menggunakan skala likert 1-5.

Ketidakpastisan lingkungan $\left(\mathrm{X}_{3}\right)$. Pengukuran dilakukan dengan 12 item indikator pertanyaan yang di kembangkan oleh Duncan, 2002. Dengan menggunakan skala likert 1-5.

3. Variabel Devenden (Variabel Y)

Variabel Dependen merupakan bagian yang ingin dijelaskan atau diprediksi dan dipengaruhi oleh bebrapa faktor lain (Robbin dalam Juliansyah, 2011:49). Variabel devenden yaituSlack anggaran (Y). Pengukuran dilakukan dengan 6 item indikator pertanyaan yang di kembangkan oleh Dunk, 1993 dalam Triana, et al,2012. Dengan menggunakan skala likert 1-5.

\section{Populasi, Sampel dan Teknik Pengambilan Sampel}

Satuan kerja perangkat manajemen suatu perusahaan yang menduduki jabtan sebagai manajer menengah (departemen head) ke bawah dengan kriteria tertentu pada hotel berbintang di Kota Bogor merupakan populasi pada penelitian ini. Sampel adalah sejumlah elemen-elemen dari populasi, sehingga sampel penelitian dan pemahaman tentang sifat atau karakteristiknya akan membuat kita menggeneralisasi sifat pada populasi (Juliansyah, 2011:148). Teknik sampling yang dipakai ialah dengan memakai purposive sampling harapannya agar mendapatkan sampel yang representatif sesuai kriteria sampel yang ditentukan. Kriteria sampel yaitu:

1. Hotel-Hotel yang memiliki struktur organisasi.

2. Kriteria jabatan sebagai Manajer (departement head) yang ikut berperan pada pengkoordinasian anggaran hotel.

3. Menjabat manajer minimal satu tahun.

Terdapat 38 hotel berbintang yang berada di Kota Bogor berdasarkan data yang diperoleh dari dinas kebudayaan dan pariwisata Kota Bogor. Masing-masing hotel didistribusikan angket atau kuesioner sebanyak 3 , dengan jumlah 114 responden.

\section{METODE ANALISIS DATA}

Sebelum melakukan analisis, data diujji serta diolah agarmemahami keyakinan responden dalam menjawab pertanyaan yaitu dengan pengujian validitas, reliabilitas dan uji Asumsi klasik. Penelitian ini uji asumsi yang dipakai yakni uji normalitas, multikolonearitas dan heterokedastisitas.

Analisis data menggunakan regresi linear berganda. Adapun persamaan regresi linear berganda pada penelitian ini yaitu sebagai berikut:

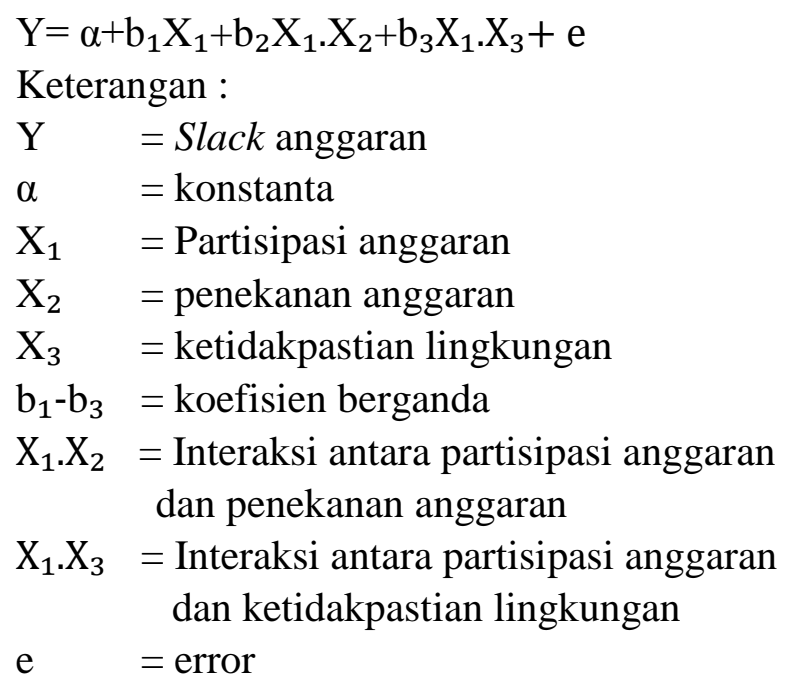

Dari analisis regresi tersebut dilakukan Uji kelayakan model (uji F) dan uji hipotesis (uji T).

\section{HASIL DAN PEMBAHASAN}

\section{Statistik Deskriptif}

Berdasarkan data yang diperoleh dari dinas kebudayaan dan pariwisata Kota Bogor, terdapat 38 hotel berbintang dengan jumlah sampel sebanyak 114 responden, hanya 20 hotel berbintang yang bersedia berpartisipasi dalam pengisian angket atau kuesioner yang berjumlah 60 responden. Jumlah kuesioner yang terkumpul dan dapat diolah sebanyak 48. Adapun rincian penyebaran dan hasil 
pengumpulan kuesioner yang diperoleh yaitu:

Tabel 1 Hasil Perolehan Data kuesioner

\begin{tabular}{|c|c|c|}
\hline Keterangan & Jumlah & Prosentase \\
\hline Kuesioner yang disebar & 60 & $100 \%$ \\
\hline Kuesioner kembali & 48 & $80 \%$ \\
\hline $\begin{array}{l}\text { Kuesioner } \\
\text { kembali }\end{array}$ & 12 & $20 \%$ \\
\hline Kuesioner dapat diolah & 48 & $80 \%$ \\
\hline
\end{tabular}

Sumber: Data Diolah (2017)

\section{Deskripsi Karakteristik Responden}

Berdasarkan perolehan data dari angket atau kuesioner penelitian. Berikut ini merupakan data demografi responden:

Tabel 2. Demografi Responden

\begin{tabular}{|c|c|c|c|c|c|}
\hline No. & Keterangan & Frequency & Percent & $\begin{array}{l}\text { Valid } \\
\text { Percent }\end{array}$ & $\begin{array}{c}\text { Cumulative } \\
\text { Percent }\end{array}$ \\
\hline \multirow[t]{6}{*}{1.} & Usia Responden & & & & \\
\hline & a. Usia 21-30th & 22 & 45,8 & 45,8 & 45,8 \\
\hline & b. Usia 31-40th & 18 & 37,5 & 37,5 & 83,3 \\
\hline & c. Usia 41-50th & 6 & 12,5 & 12,5 & 95,8 \\
\hline & d. Usia diatas 50th & 2 & 4,2 & 4,2 & 100,0 \\
\hline & Total & 48 & 100,0 & 100,0 & \\
\hline \multirow[t]{6}{*}{2.} & Pendidikan Terakhir & & & & \\
\hline & a. SMA & 6 & 12,5 & 12,5 & 12,5 \\
\hline & b. D1 & 3 & 6,3 & 6,3 & 18,8 \\
\hline & c. D3 & 12 & 25,0 & 25,0 & 43,8 \\
\hline & d. $S 1$ & 27 & 56,3 & 56,3 & 100,0 \\
\hline & Total & 48 & 100,0 & 100,0 & \\
\hline \multirow[t]{4}{*}{3.} & Jenis Kelamin & & & & \\
\hline & a. Laki-laki & 36 & 75,0 & 75,0 & 75,0 \\
\hline & b. Perempuan & 12 & 25,0 & 25,0 & 100,0 \\
\hline & Total & 48 & 100,0 & 100,0 & \\
\hline \multicolumn{6}{|c|}{ 4. Usia Masa Kerja } \\
\hline & a. Masa Kerja 1-10 th & 46 & 95,8 & 95,8 & 95,8 \\
\hline & b. Masa Kerja 11-20 th & 2 & 4,2 & 4,2 & 100,0 \\
\hline & Total & 48 & 100,0 & 100,0 & \\
\hline
\end{tabular}

\section{Pengujian Instrumen}

\section{Uji Validitas}

Uji validitas bertujuan memperhatikan kepantasan pertanyaan dalam kuesioner yang mendefinisikan sebuah variabel. Uji ini untuk melihat valid tidaknya kuesioner yang dilakukan melalui menilai korelasi masingmasing pernyataan dengan nilai total pada masing-masing variabel. Hasilnya dipertimbangkan dengan $r_{\text {tabel }} \mid d f=n-k$ dengan tingkat kesalahan 5\% (juliansyah, 2011:169). Jika $r_{\text {tabe }}<<r_{\text {hitung, maka butir soal }}$ disebut valid. Hasil perhitungan berdasarkan nilai $\quad r_{\text {hitung }}>r_{\text {tabel }}$ sebesar 0,2845 untuk $\mathrm{df}=48-2=46, \quad \alpha=0,05 \quad($ uji dua sisi ) dinyatakan valid dan sebaliknya.

Berdasarkan pengujian yang dilakukan menunjukan semua pertanyaan dari semua variabel memiliki nilai pearson correlation diatas 0,2845 dengan taraf signifikansi 0,000 sehingga semua pertanyaan lulus uji validitas.

\section{Uji Reliabilitas}

Uji Reliabilitas bermaksud mendeteksi kestabilan / keandalan ukuran dan konsistensi jika dilakukan perhitungan ulang. Keandalan pengukuran diketahui menggunakan nilai Cronbach's Alpha yang menunjukan seberapa baiknya item setiap variabel masing-masing dalam kumpulan korelasi positif satu sama lain.

Hasil pengujian reliabilitas semua pertanyaan menunjukan pada variabel partisipasi anggaran sebesar 0,814, penekanan anggaran sebesar 0,8 862, ketidakpastian lingkungan sebesar 0,670 sertaslack anggaran sebesar 0,715. Hal tersebut menggambarkan alat yang dipakai dinyatakan reliabel dan akan sama apabila dlakukan pengujian ulang.

\section{Uji Asumsi Klasik}

\section{Uji Normalitas}

Uji normalitas pertama menggunakan metode grafik histogram dan normal pp plots regression. Berikut adalah hasil pengujian menggunakan grafik histogram dan normal pp plots regression: 


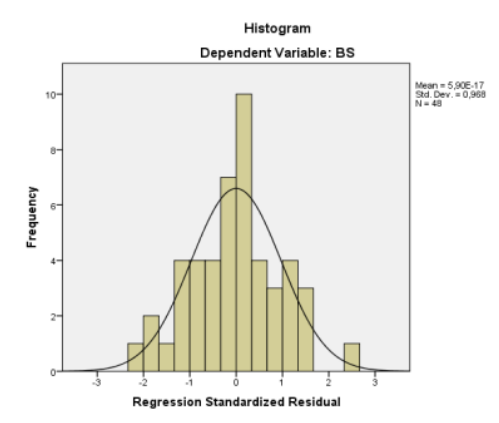

Gambar 1

Grafik histogram disimpulkan distribusi membentuk pola seperti lonceng. Hal ini membuktikan secara subyektif data normal.

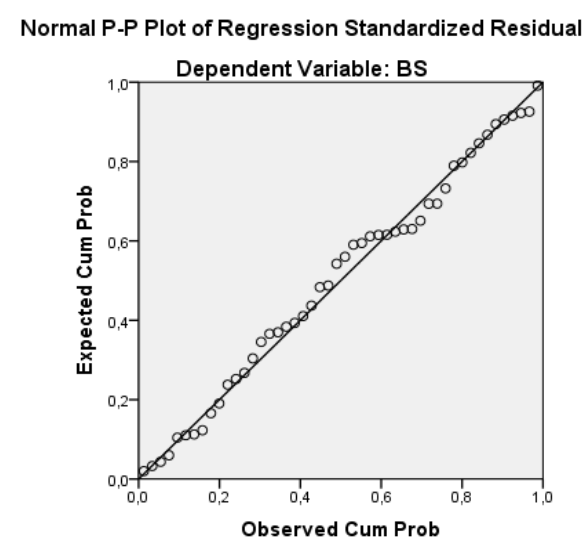

\section{Gambar 2}

Jika dilihat dari grafik normal p-p plot regression terlihat bahwa sebaran data mengikuti arah garis diagonal atau pada titiktitik menyebar dan mengikuti arah arah garis diagonal. Jadi disimpulkan data normal.

Pada uji asumsi klasik, untuk lebih meyakinkan data normal selanjutnya peneliti melakukan pengujian dengan metode statistikal one sample kolmogrov smirnov. Hasil menunjukan dilihat nilai Asymp. Sig. (2-tailed) atau uji dua sisi sebesar 0,935 lebih besar $0,05(0,935>0,05)$, sehingga data berdistribusi normal.

\section{Uji Multikolonearitas}

Uji multikolinieritas bermaksud mengetes model regresi bila terdapat ada korelasi antar variabel independen. Uji ini menggunakan nilai tolerance dan VIF (varian inflation factor) yang memiliki standar pengambilan keputusan nilai VIF harus lebih kecil $10(\mathrm{VIF}<10)$ artinya tidak ada hubungan korelasi antara variabel atau bebas multikolonearitas. Sebaliknya apabila nila VIF lebih besar 10 (VIF >10), maka terjadi hubungan linearitas antara model regresi.

Hasil pengujian menunjukan bahwa pada semua variabel independen memiliki nilai VIF masing-masing yaitu partisipasi anggaran sebesar 1,899, penekanan anggaran sebesar 1,845, dan ketidakpastian lingkungan sebesar 1,050 yang artinya semua variabel memiliki nilai VIF lebih kecil 10 sehingga dikatakan model regresi penelitian ini tidak terjadi multikolonearitas.

\section{Uji Heterokedastisitas}

Uji heterokedastisitas bermaksud memahami model regresi terjadi gejala ketidaksamaan varians dari residual semua pengamatan. Pengujian penelitian menggunakan grafik scatter plots yakni :

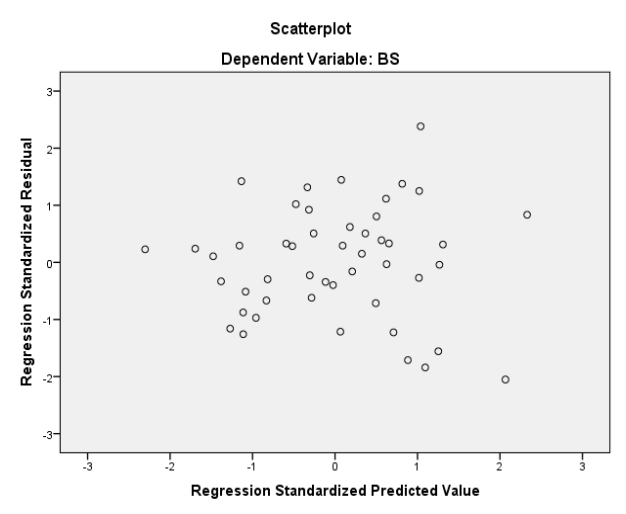

\section{Gambar 3}

Berdasarkan gambar 4.3 dilihat titiktitik tidak membentuk pola tertentu, dan titiktitik menyebar disekitar garis angka nol di sumbu Y. Jadi dijelaskan data bebas heterokedastisitas.

\section{Analisis Regresi Berganda}

Adapun pengujian analisis regresi berganda dengan model moderasi diolah dengan SPSS 20.0. Adapun persamaan regresi berganda pada model moderasi sebagai berikut: 


$$
\begin{aligned}
\mathrm{Y}= & 23,386-0,873 \mathrm{X}_{1}+0,007 \mathrm{X}_{1}, \mathrm{X}_{2}+ \\
& 0,013 \mathrm{X}_{1} \cdot \mathrm{X}_{3}
\end{aligned}
$$

Dimana :

$\begin{array}{lll}\mathrm{Y} & =\text { Slack Anggaran } \\ \mathrm{X} 1 & =\text { Partisipasi Anggaran } & \\ \mathrm{X} 2 & =\text { Penekanan Anggaran } & \\ \mathrm{X} 3 & =\text { Ketidakpastian Lingkungan } \\ \mathrm{X} 1 . \mathrm{X} 2 & =\text { Interaksi Antara Partisipasi } \\ & \text { Anggaran dengan Penekanan } \\ & \text { Anggaran } & \\ \mathrm{X} 1 \mathrm{X} 3 & & \text { Interaksi Antara Partisipasi }\end{array}$

X1.X3 = Interaksi Antara Partisipasi Anggaran dengan Ketidakpastian Lingkungan.

Interpretasi dari persamaan diaas, dapat dijelaskan,

a. Nilai konstanta sebesar 23,386 artinya, menunjukan pengaruh partisipasi anggaran, hubungan moderasi antara partisipasi anggaran dengan penekanan anggaran serta hubungan moderasi partisipasi anggaran dengan ketidakpastian lingkungan. Jika nilainya adalah sama dengan 0, maka slack anggaran diprediksi sebesar 23,386 .

b. Koefisien regresi partisipasi anggaran $\left(\mathrm{X}_{1}\right)=-0,873$ berarti jika variabel bebas lain nilainya tetap serta partisipasi anggaran $\left(\mathrm{X}_{1}\right)$ mengalami peningkatan sebesar satu unit, maka slack anggaran (Y) akan mengalami penurunan sebesar 0,873 satuan unit. Koefisien bernilai negatif artinya terjadi keterkaitan negatif antar partisipasi anggaran dengan slack anggaran, dimana semakin tinggi patisipasi anggaran semakin rendah kecenderungan timbulnya slack anggaran.

c. Koefisien regresi pada hubungan moderasi variabel partisipasi anggaran dengan penekanan anggaran bernilai 0,007 berarti jika variabel lain nilainya tetap serta ikatan antar partisipasi anggaran dengan penekanan anggaran mengalami peningkatan satu unit, maka slack anggaran (Y) mengalami peningkatan sebesar 0,007 satuan unit.

d. Koefisien regresi pada hubungan moderasi antar variabel partisipasi anggaran dengan ketidakpastian lingkungan bernilai 0,013 berarti jika variabel lain nilainya tetap sertaikatan antar partisipasi anggaran serta ketidakpastian lingkungan kengalami peningkatan satu unit, maka slack anggaran (Y) mengalami peningkatan sebesar 0,013 satuan unit.

\section{Koefisien Korelasi}

Analisis ini dipakai menghitung ukuran keterkaitan antar dua variabel yang diteliti yakni variabel bebas dengan variabel terikat. Adapun kriteria keputusan diambil dengan melihat nilai $\mathrm{R}$ pada hasil pengujian:

Tabel 3 Hasil Analisis Korelasi Berganda Model Summary ${ }^{b}$

\begin{tabular}{lrrrr}
\hline Model & $\mathrm{R}$ & $\begin{array}{c}\mathrm{R} \\
\text { Square }\end{array}$ & $\begin{array}{r}\text { Adjusted } \\
\text { R Square }\end{array}$ & $\begin{array}{r}\text { Std. Error of } \\
\text { the Estimate }\end{array}$ \\
\hline 1 &, $474^{\mathrm{a}}$ &, 224 &, 172 & 2,701 \\
\hline
\end{tabular}

a. Predictors: (Constant), X1.X3, X1.X2, PA

b. Dependent Variable: BS

\section{Sumber: Data Primer Diolah (2017)}

Tabel 3 di atas menunjukan nilai $\mathrm{R}$ sebesar 0,474 yang berarti menunjukan tingkat hubungan yang "sedang" antar variabel bebas partisipasi anggaran, hubungan moderasi partisipasi anggaran dengan penekanan anggaran, dan hubungan moderasi partisipasi anggaran dengan ketidakpastian lingkungan serta variabel terikat slack anggaran.

\section{Koefisien Determinasi}

Berdasarkan tabel 3 diatas, diperoleh nilai $R$ Square atau $\left(\mathrm{R}^{2}\right)$ sebesar 0,224 atau $(22,4 \%)$. Hal ini menunjukan sumbangan partisipasi anggaran, hubungan moderasi partisipasi anggaran dengan penekanan anggaran, dan hubungan moderasi partisipasi anggaran dengan ketidakpastian lingkungan secara simultan padaslack anggaran sebagai 
variabel terikat (dependen) dengan persentase sebesar 22,4\%. Sedangkan sisanya sebesar $77,6 \%(100 \%-22,4 \%)$ dipengaruhi oleh faktor lain yang tidak dimasukan pada penelitian ini.

\section{Pengujian Hipotesis \\ Uji F}

Pengaruh simultan pada partisipasi anggaran padaslack anggaran denga penekanan dan ketidakpastian lingkungan sebagai variabel moderating dilihat dari hasil output uji ANOVA:

Tabel 4 Hasil Uji F (Uji Simultan)

\begin{tabular}{|c|c|c|c|c|c|c|}
\hline \multicolumn{7}{|c|}{ ANOVA $^{a}$} \\
\hline & Model & $\begin{array}{l}\text { Sum of } \\
\text { Squares }\end{array}$ & Df & $\begin{array}{l}\text { Mean } \\
\text { Square }\end{array}$ & $\mathrm{F}$ & Sig. \\
\hline \multirow{3}{*}{1} & $\begin{array}{l}\text { Regressi } \\
\text { on }\end{array}$ & 92,906 & 3 & 30,969 & 4,244 &, $010^{\mathrm{b}}$ \\
\hline & Residual & 321,074 & 44 & 7,297 & & \\
\hline & Total & 413,979 & 47 & & & \\
\hline
\end{tabular}

a. Dependent Variable:SA

b. Predictors: (Constant), X1.X3, X1.X2, PA

\section{Sumber: Data Primer Diolah (2017)}

Berdasarkan pengujian menunjukan hasil output dari ANOVA mempunyai nilai

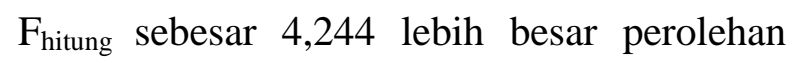
nilai $\mathrm{Ft}_{\text {abel }}$ sebesar 2,82 (4,244 > 2,82), maka maka $\mathrm{H}_{\mathrm{o}}$ ditolak serta $\mathrm{H}_{\mathrm{a}}$ diterima. Sehingga ketetapannyaterdapat pengaruh signifikan secara simultan antara partisipasi anggaran padaslack anggaran dengan penekanan anggaran serta ketidakpastian lingkungan sebagai variabel moderating,

\section{Uji t}

Hasil uji t secara parsial di variabel independen partisipasi anggaran serta variabel moderasi penekanan anggaran serta ketidakpastian lingkungan terhadap slack anggaran yakni:

Tabel 5 Hasil Uji t ( Uji Parsial)

\begin{tabular}{|c|c|c|c|c|c|}
\hline \multicolumn{6}{|c|}{ Coefficients $^{\mathrm{a}}$} \\
\hline \multirow[t]{2}{*}{ Model } & \multicolumn{2}{|c|}{$\begin{array}{l}\text { Unstandardized } \\
\text { Coefficients }\end{array}$} & \multirow{2}{*}{$\begin{array}{c}\begin{array}{c}\text { Standardized } \\
\text { Coefficients }\end{array} \\
\text { Beta }\end{array}$} & \multirow[t]{2}{*}{$\mathrm{T}$} & \multirow[t]{2}{*}{ Sig. } \\
\hline & B & Std. Error & & & \\
\hline (Constant) & 23,286 & 3,320 & & 7,014 & ,000 \\
\hline PA &,- 873 &, 374 & $-1,101$ & $-2,333$ & ,024 \\
\hline${ }^{1} \quad X 1 . X 2$ & ,007 & ,007 & , 466 & 1,090 &, 282 \\
\hline X1.X3 & ,013 & ,005 &, 923 & 2,842 & ,007 \\
\hline
\end{tabular}

\section{Sumber: Data Primer Diolah (2017)}

Nilai $r_{\text {tabel }}$ diperoleh dengan menggunakan tingkat kepercayaan 95\% $(\mathrm{a}=5 \%)$ dengan derajat kebebasa (df) $n-k-1$ atau 48-3-1= 44 (n adalah jumlah responden dan $\mathrm{k}$ adalah jumlah variabel independen), Sehingga diperoleh nilai $t_{\text {tabel }}$ sebesar 2,0153.

a. $\mathrm{H}_{1}=$ Partispasi Anggaran Berpengaruh Terhadap Slack Anggaran.

Berdasarkan hasil pengolahan data regresi menunjukan variabel partisipasi

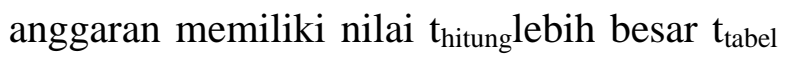
yaitu $-2,333>2,0153$ dan nilai signifikansi sebesar 0,024 lebih kecil dari 0,05 berarti partisipasi anggaran berpengaruh negatif serta signifikan terhadap slack anggaran.

Hal ini sejalan dengan hasil penelitian sebelumnya oleh Pamungkas et al (2014) serta Dewi dan Erawati (2014) yang menyatakan partisipasi anggaran berpengaruh negatif signifkan terhadap budgetary slack. Artinya partisipasi yang tinggi maka akan mengurangi slack anggaran, diduga karena semakin tinggi keikutsertaan bawahan serta kinerja karyawan cukup aktif pada perancangan anggaran yang mengurangi slack anggaran. Pada partisipasi yang tinggi para manajer memiliki sikap integritas dan moralitas individu masi sangat baik serta komunikasi yang sangat baik dan komitmen kerja yang baik dapat meminimalkan kecenderungan timbulnya slack. Manajer secara profesional berkomitmen untuk melakukan tindakan sesuai dengan tujuan organisasi dan trust (kepercayaan) atasan pada bawahan yang membangun sikap 
integritas lebih berperan nyata. Sehingga disimpulkan semakin tinggi partisipasi anggaran maka semakin rendah kemungkinan slack anggaran.

b. $\mathrm{H}_{2}=$ Penekanan Anggaran Memoderasi Hubungan Antara Partisipasi Anggaran Terhadap Slack Anggaran.

Berdasarkan hasil pengolahan uji regresi menunjukan hasil interaksi antara penekanan anggaran dengan partisipasi anggaran variabel yang memiliki nilai $t_{\text {hitung }}$ lebih kecil $t_{\text {tabel }}(1,090<2,0153)$ dan nilai signifikansi lebih besar dari 0,05 (0,282> $0,05)$ yang artinya penekanan anggaran secara parsial tidak berpengaruh dan signifikan serta tidak berupa variabel moderasi pada hubungan antara partisipasi anggaran padaslack anggaran.

Temuan ini tidak sejalan dengan penelitian Triana et al (2012), Veronica dan Krisnadewi (2009), Jaya (2013), Irfan et al (2016), Dewi dan Erawati (2014) dan Tristanto (2014) yang menyatakan pada penekanan anggaran berpengaruh signifikan padaslack anggaran. Penekanan anggaran yang rendah bisa mengurangi slack anggaran. Pernyataan ini disebabkan karena adanya suatu nilaian kinerja yang berbasis anggaran dengan dirangsang oleh adanya sautu reward atau kompensasi apabila target anggaran tercapai tidak mendorong karyawan atau manajer untuk melakukan slack anggaran karena manajer memiliki sikap integritas yang tinggi dan komitmen kerja secara profesional.

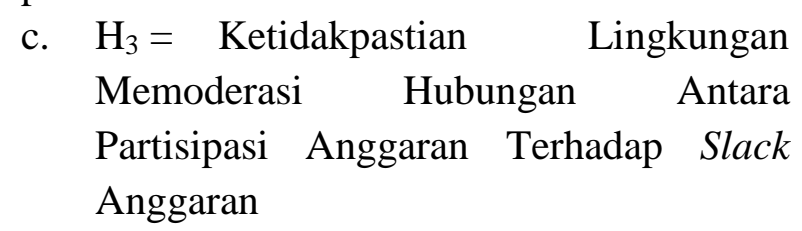

Berdasarkan hasil pengujian uji regresi menunjukan hasil interaksi antara ketidakpastian lingkungan dengan partisipasi anggaran pada slack anggaran menunjukan $t_{\text {hitung }}$ lebih besar $t_{\text {tabel }}(2,842>2,0153)$ dan nilai signifikansi lebih kecil $0,05(0,007<$ $0,05)$ yang berarti bahwa pada variabel ketidakpastian lingkungan secara parsial berpengaruh signifikan dan terlibat sebagai variabel moderasi (memperkuat) pada hubungan antar partisipasi anggaran padaslack anggaran. Disimpulkan jika variabel ketidakpastian lingkungan merupakan variabel moderasi atau Quasi Moderasi.

Hasil ini sepaham dengan penelitian sebelumnya oleh Kartika (2010) dimana kondisi ketidakpastian lingkungan yang tinggi, partisipasi anggaran bisa berpengaruh negatif pada slack anggaran. Berarti tingginya tingkat partisipasi maka slack anggaran akan semakin menurun dan sebaliknya apabila kondisi ketidakpastian lingkungan rendah, partisipasi anggaran jadi berpengaruh positif terhadap slack anggaran. Berarti tingginya partisipasi anggaran akan semakin meningkat juga slack anggaran yang ditimbulkan (Kartika, 2010). Pada keadaan ketidakpastian lingkungan tinggi (tidak stabil), para manajer diduga mengalami kesulitan untuk memprediksi keadaan masa datang karena kondisi tidak stabil / cepat berubah-ubah. Namun dengan seiiring kemajuan teknologi dan informasi yang semakin maju, membuat kemudahan untuk para manajer menggali informasi-informasi dibutuhkan dalam meningkatkan keakuratan sehingga para manajer dapat memprediksi keadaan masa mendatang dan membuat keputusan.

\section{Kesimpulan}

1. Hasil uji regresi uji $t$, partisipasi anggaran secara parsial memiliki pengaruh negatif serta signifikan terhadap slack anggaran hotel-hotel berbintang di Kota Bogor. Berarti tingginya partisipasi anggaran akan cenderung mengurangi terciptanyaslack anggaran hotel-hotel berbintang di Kota Bogor.

2. Hasil uji regresi uji t,interaksi antara variabel partisipasi anggaran serta penekanan anggaran secara parsial tidak memiliki pengaruh signifikan pada slack 
anggaran hotel-hotel berbintang di Kota Bogor. Artinya bahwa pada penelitian ini variabel penekanan anggaran tidak mampu berperan sebagai variabel moderating (memperkuat atau memperlemah) hubungan partisipasi anggaran pada slack anggaran.

3. Hasil uji regresi parsial atau uji t, interaksi antara variabel partisipasi anggaran serta ketidakpastian lingkungan memiliki pengaruh signifikan terhadap slack anggaran hotel-hotel berbintang di Kota Bogor. Artinya bahwa variabel ketidakpastian lingkungan memoderasi (memperkuat) hubungan pengaruh antara partisipasi anggaran padaslack anggaran. ketidakpastian lingkungan berperan sebagai variabel moderating dan merupakan Quasi Moderating.

\section{DAFTAR PUSTAKA}

Anthony, Robert N, Vijay Govindrajan, dan Drs. R. Suyoto Bakir, 2011. Sistem Pengendalian Manajemen. Edisi

12, Tangerang Selatan.

Baedermaeker, Jolien De dan Werner Brruggeman, 2015. The Impact of Participation in Strategi Planning on Managers' Creation of Bugdetary Slack :The Mediating role of Autonomous Motivation and Affective Organization Commitmen. Jurnal Management Research.

Dewi, Nyoman Purmita dan Ni Made Adi Erawati, 2014. Pengaruh Partisipasi Anggaran, informasi asimetri, Penekanan Anggaran dan Komitmen Organisasi Pada Senjangan Anggaran. E-jurnal Universitas Udayana. ISSN: 2302 8556. 476-486.

Dharmanegara, Ida Bagus Agung, 2010. Penganggaran Perusahaan: Teori dan Aplikasi. Edisi Pertama, Graha Ilmu, Yogyakarta.
Dunk, Alan S, 1989. Budget Emphasis, BudgetaryParticipation and Managerial Performance: A Note. Journal Accounting Organization and Society. Vol:14. 321-324.

Dunk, Alan S, 1993. The Effect of Budget Emphasis and Information Asymetry on the Relation Beetwen Budgetary Participation and Slack. The Accounting Review. Vol:68. No.2.

Fakultas Ekonomi Universitas Djuanda, 2016. Pedoman Penulisan Skripsi dan Karya Ilmiah. Bogor

Horngren, Dkk, 2016. Pengantar Akuntansi Manajemen. Edisi Keenam Belas, Jilid 1, Erlangga.

Ikhsan, Arfan dan Muhammad Ishak, 2005.

Akuntansi Keperilakuan. Salemba Empat, Jakarta.

Indriani, Listya dan M. Yusuf, 2014. Pengaruh Partisipasi Anggaran Terhadap Kesenjangan Anggaran Dengan Budaya Organisasi Sebagai Variabel Pemoderasi (Studi Pada Rumah Sakit Umum Daerah (RSUD) dan RSI Sultan Agung di Kota Semarang). Presta (Vol 13), ISSN 1411-1497.

Irfan, Muh, Budi Santoso dan Lukman Effendi, 2016. Pengaruh Partisipasi Anggaran Terhadap Senjangan Anggaran Dengan Asimetri Informasi, Penekanan Anggaran dan Komitmen Organisasional Sebagai Variabel Pemoderasi. Jurnal Akuntansi dan Investasi. Vol.17. No.2. Hal:158-175.

Jaya, M. Faruq Dwi, 2013. The Effect Of Budget Participation, Asymetric Information, Budget Emphasis, And Organization Commitment On Budgetary Slack In Pemerintah Kota Pasuruan. Jurnal Ilmiah FEB Universitas Brawijaya.

Kartika, Andi, 2010. Pengaruh Komitmen Organisasi dan Ketidakpastian Lingkungan Dalam Hubungan 
Antara Partisipasi Anggaran Dengan Senjangan Angaran (Studi Empirik Pada Rumah Sakit Swasta di Kota Tangerang). Kajian Akuntansi, ISSN:1979-4886. Hal: 39-60.

Kenis, Izzetin, 1979. Effect Of Budgetary Goal Characteristics on Managerial Attitudes and Performance. The Accounting Review. Vol. 54. No. 4.

Lau, Chong M dan Jeng Je Tan, 1998. The Impact of Budget Emphasis, Particiipation, And Task Difficulty On Managerial Performance : A Cross- Curcural Study of The Financial Services Sector. Journal Management Accounting Research. 163-183.

Merchant, Kenneth A, 1985. Budgeting And The Propensity To Create Budgetary Slack. Journal Accounting and Society. Vol:10. 201-2010.

Mulyani, Rina, 2012. Pengaruh Komitmen Organisasi dan Ketidakpastian Lingkungan terhadap Hubungan Antara Partisipasi Anggaran Dengan Senjangan Anggaran. Skripsi Sarjana, Fakultas Ekonomi dan Ilmu Sosial, Universitas Islam Negeri Sultan Syarif Kasim, Riau.

Munandar, M, 2007. Budgeting. Edisi kedua, BPFE, Yogyakarta.

Nafarin, M, 2004. Penganggaran Perusahaan. Edisi Pertama, Salemba Empat, Jakarta.

Noor, Dr. Juliansyah 2011. Metodologi Penelitian : Skripsi, Tesis, Disertasi dan Karya ilmiah. Edisi Pertama, Kharisma Putra Utama.

Pamungkas, Adiputra dan Sulindawati, 2014. Pengaruh Partisipasi Anggaran, Informasi Asimetri, Budaya Organisasi, Kompleksitas Tugas, Reputasi, Etika, dan Self Esteem TerhadapBudgetary Slack (Studi Pada Satuan Kerja Perangkat Daerah Kabupaten Jembrana). E- jurnal S1 Ak Universitas Ganesha (Vol 2).

Rohmania, Fathiatur, 2014. Pengaruh Partisipasi Anggaran Terhadap Slack Anggaran Dengan Komitmen Organisasi, Ketidakpastian Lingkungan, dan Motivasi Sebagai Pemoderasi (Studi Empiris Pegawai Pemerintahan Se-Kabupaten Kudus). Fakultas Ekonomi Muria Kudus.

Setiyanto, Arif Budi, 2011. Pengaruh Informasi Asimetri dan Partisipasi Pengangaran Terhadap Komitmen Organisasi Serta Dampaknya Terhadap Timbulnya Senjangan Anggaran (Studi Kasus pada PT. Suara Merdeka Pres Semarang). Universitas Diponegoro, Semarang.

Setiawan, Bambang Moertono dan Imam Ghozali, 2016. The Effect of Budget Participation and Budgetary Slack In Local Government With Organization Commitment and Environmental Uncertainty As The Moderating Variabel. Ijaber, Vol:14. No.10:7099- 7120.

Sujana, I Ketut, 2010. Pengaruh Partisipasi Anggaran, Komitmen Organisasi, Asimetri Informasi, dan Ketidakpastian Lingkungan Terhadap Budgetary Slack Pada Hotel-Hotel Berbintang di Kota Denpasar. Audi Jurnal Akuntansi dan Bisnis. Vol:5. No 2.

Triana, Maya, Yuliusman dan Wirmie Eka Putra, 2012. Pengaruh Partisipasi Anggaran, Budget Emphasis, dan Locus of Control Terhadap Slack Anggaran (Survei pada Hotel Berbintang di Kota Jambi). E-jurnal Binar Akuntansi (Vo1) ISSN:23031522.

Tristianto, Arie dan Akhmad Riduwan, 2014.

Pengaruh Partisipasi Anggaran terhadap Budget Slack Dengan Asimetri dan Tekanan Anggaran Sebagai Variabel Pemoderasi. 
Jurnal Ilmu dan Riset Akuntansi. Vol. 3. No.

5.

Trihendradi, C, 2012. Step by Step SPSS 20

Analisis Data Statistik. ANDI.

Yogyakarta.

Veronica, Amelia dan Komang Ayu

Krisnadewi, 2008. Pengaruh

Partisipasi Anggaran, Penekanan

Anggaran, Komitmen Organisasi

dan Kompleksitas Tugas Terhadap

Budgetary Slack pada Bank

Perkreditan Rakyat (BPR) di

Kabupaten Badung. Audi, Jurnal

Akuntansi dan Bisnis. Vol.. 4. No.

1:20-28

Young, S. Mark, 1985. Participative

Budgeting: The Effect of Risk and

Asymmetric information on

budgetary slack. Journal of

Accounting Research Vol 23.No.2 :

829-842.

Widanaputra, A A dan Mimba, 2014. The

Influence of Participative budgeting on Budgetary Slack in Composing Local Government Budget in Bali Province. Journal Social and Behavioral Science. 391-396.

Mei 2017.

http://www.disbudpar.go.id (diakses 